\title{
SOLITARY PLASMACYTOMA OF THE STERNUM
}

\author{
Singh $\mathbf{Y}^{1}$ \\ Sayami G. ${ }^{2}$ \\ Manandhar T. ${ }^{3}$ \\ Khakurel M. ${ }^{4}$
}

\section{ABSTRACT:}

A 40 year old male patient with solitary plasmacytoma of the sternum diagnosed by fine needle aspiration biopsy is reported. There was no evidence of multiple myeloma in this case. The patient was successfully treated with radiation therapy and adjuvant combination chemotherapy.

\section{Key Words: Plasmacytoma, Solitary tumour, Needle biopsy, Radiotherapy}

\section{INTRODUCTION:}

Primary tumours of the sternum represent about $1 \%$ of all bone tumours and are usually malignant. ${ }^{1}$ Solitary plasmacytoma of bone or soft tissues is a localized monoclonal gammopathy which is different from a disseminated neoplastic monoclonal gammopathy, multiple myeloma. It constitutes $7 \%$ of all plasma cell malignancies. ${ }^{2}$ Because of the rarity of the disease, many aspects of the disease remain to be elucidated. Herein we report a case of solitary plasmacytoma of the sternum without evidence of multiple myeloma who was successfully treated with radiation therapy.

\section{CASE REPORT:}

A 40-year-old man, clerk by occupation from Terai region was seen at Department of Surgery, Tribhuvan University Teaching Hospital, Kathmandu, Nepal with an anterior upper chest wall mass. Swelling of the midline sternoclavicular area, noted one year earlier had increased gradually. There was no pain or discomfort.

Physical examination was normal exam a soft, nontender, fixed mass $10 \times 6 \times 3 \mathrm{~cm}$ involving the anterior upper sternum (Fig.1). There were no pulsation or bruits. Routine blood counts and

1. Assistant Professor, Department of Surgery, T.U. Teaching Hospital

2. Associate Professor, Department of Pathology, T.U. Teaching Hospital

3. Consultant Radiation Oncologist, Bir Hospital, Kathmandu

4. Professor and Head, Department of Surgery, T.U. Teaching Hospital

Address for correspondence : $\quad$ Dr. Yogendra Singh, Assistant Professor, Department of Surgery, TUTH G.P.O. Box No.: 5204, Kathmandu, Nepal.

Tel./Fax: +977-1-413985, email: yp_singh@hotmail.com 


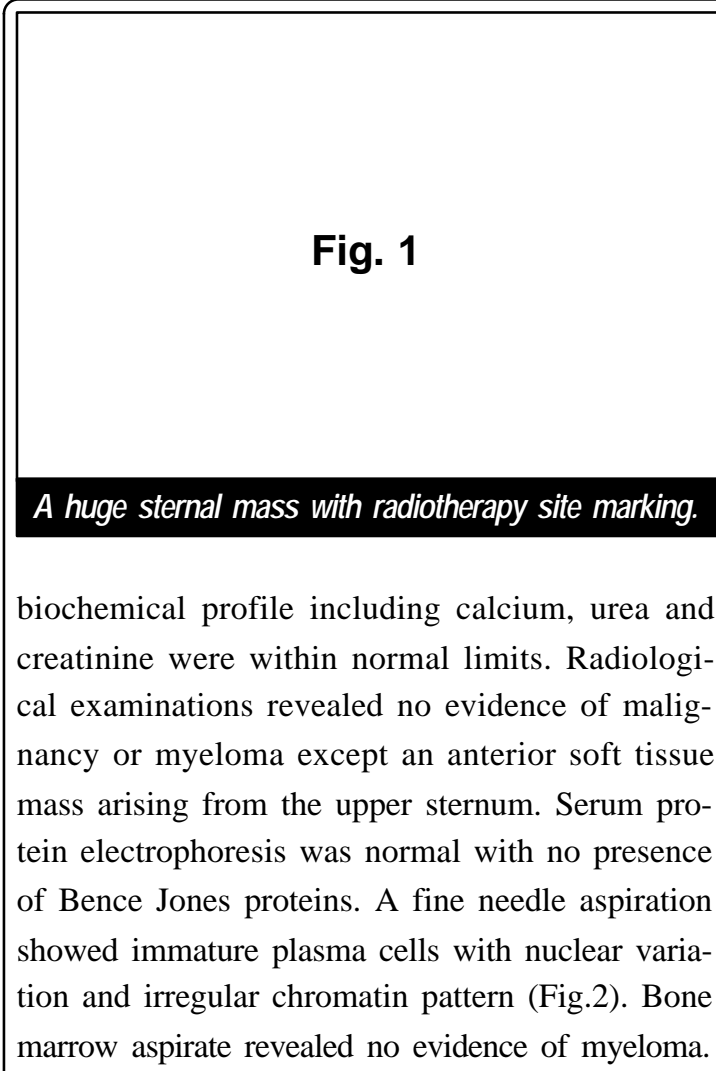

marrow aspirate revealed no evidence of myeloma.

Fig. 2

Needle biopsy of Solitary plasmacytoma H \& E Stain x 40

After the diagnosis of solitary plasmacytoma of the sternum had been confirmed, primary radiotherapy was planned. The patient received 2 Gy per day, 5 days a week for 5 weeks from a cobalt 60 machine at radiotherapy unit, Bir Hospital, Kathmandu. The swelling disappeared with radiotherapy. Pre and post radiotherapy period was uneventful. The patient was subjected to adjuvant combination chemotherapy with oral melphalan and prednisone. One year after radiotherapy the patient is doing well with no evidence of local or distant recurrence or myeloma.

\section{DISCUSSION:}

Patients with solitary plasma cell malignant lesions in bone or soft tissue usually have fewer than $5 \%$ plasmacytes in bone marrow examinations. Several other factors differentiate patients with solitary lesions from those with multiple myeloma. Age at presentation tends to be younger in case of solitary plasmacytoma with a higher percentage of male patients. Typical radiographic presentation of solitary plasmacytoma will be fracture associated with soft tissue mass whereas punched out lesions are characteristic of multiple myeloma.

\section{Table I \\ Diagnostic Criteria for Solitary Plasmacytoma}

i. Presence of a solitary bone lesion.

ii. A biopsy showing plasma cell histology.

iii. Absence of myeloma cells in the bone marrow aspirate.

iv. Absence of anemia, hypercalcemia and renal involvement.

Table I illustrates the diagnostic criteria for solitary plasmacytoma. ${ }^{3}$ Detection of a monoclonal component in the serum or urine does not exclude the diagnosis of solitary plasmacytoma. However, patients with Bence Jones - only myeloma have been assessed for measured tumour cell burden, and they appear to represent a higher risk subgroup with a higher tumour cell mass and shorter survival. $^{4}$

Based on the well known radiosensitivity of the plasma cell tumour, radiotherapy is a well established treatment for solitary plasmacytoma or extramedullary plasmacytomas. Radiation doses of 
40 to $60 \mathrm{~Gy}$ in 4 to 6 weeks, using megavoltage fields that adequately encompass necessary soft tissue and bony structures, have been proposed. In primary bony lesions, the entire medullary cavity of the bone must be encompassed because of the possibility of medullary cavity spread.

Several studies have demonstrated the distinct difference in the ultimate prognosis between patients with solitary lesions in bone and those with multiple or extramedullary lesions..$^{5-7}$ Patients with solitary bony lesions experience significant longer survivals. These patients should be followed up for longer duration because multiple myeloma develops in half of patients with solitary plasmacytoma usually within 10 years of diagnosis. ${ }^{3}$

\section{REFERENCE:}

1. Martini N, Huvos A, Smith J, Beattie EJ Jr. Primary malignant tumours of the sterunum. Surgery Gynecol Obstet 138: 391-395: 1974.

2. Woodruff RK, Whittle JM, Malpas JS. Solitary plasmacytoma. I. Solitary plasmacytoma of bone. Cancer 43: 2340-2343; 1979.
3. Bataille R and Sany J. Solitary myeloma: clinical and prognostic features of a review or 114 cases. Cancer 48: 845-851; 1981.

4. Durie BGM, Cole PW, Chen HSG, et al. Synthesis and metabolism of Bence Jones protein and calculation of tumour burden in patients with Bence Jones myeloma. Br J Hematol 47: 7; 1981.

5. Crowin $\mathbf{J}$ and Lindberg RD. Solitary plasmacytoma of bone versus extramedullary plasmacytoma and their relationship to multiple myeloma. Cancer 43: 1007-1013; 1979.

6. Knowling M, Harwood A, Bergsagel DE. A comparison of extramedullary plasmacytoma with multiple and solitary plasma cell tumours of bone. J Clin Oncol 1: 225-262; 1983.

7. Woodruff RK, Malpas JS, White FE. Solitary plasmacytoma. II. Solitary plasmacytoma of bone. Cancer 43: 2344: 1979.

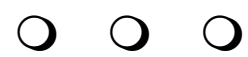

